\title{
High Wilms' tumor 1 mRNA expression correlates with basal-like and ERBB2 molecular subtypes and poor prognosis of breast cancer
}

\author{
XIAO-WEI QI $^{1 *}$, FAN ZHANG $^{1 *}$, XIN-HUA YANG $^{1}$, LIN-JUN FAN $^{1}$, YI ZHANG $^{1}$, \\ YAN LIANG ${ }^{1}$, LIN REN ${ }^{1}$, LING ZHONG ${ }^{1}$, QING-QIU CHEN ${ }^{1}$, KONG-YONG ZHANG ${ }^{1}$, \\ WEI-DONG ZANG ${ }^{2}$, LI-SHAN WANG ${ }^{2}$, YING ZHANG ${ }^{3}$ and JUN JIANG ${ }^{1}$
}

\author{
${ }^{1}$ Breast Disease Center, Southwest Hospital, Third Military Medical University, Chongqing; ${ }^{2}$ College of Life Sciences and \\ Biotechnology, Shanghai Jiaotong University, Shanghai, P.R. China; ${ }^{3}$ City College of San Francisco, San Francisco, CA, USA
}

Received March 12,2012; Accepted May 23, 2012

DOI: 10.3892/or.2012.1906

\begin{abstract}
The role of Wilms' tumor 1 (WT1) in breast cancer and the relationship between WT1 expression and clinicopathological factors, molecular subtypes and prognosis of breast cancer patients have not been clarified to date. We used publicly available microarray datasets of 266 early breast cancer patients to perform bioinformatics analysis on the relationship between WT1 mRNA expression and breast cancer. Results showed that WT1 mRNA expression was correlated with higher histological grades, ER-negative and basal-like and ERBB2 molecular subtypes in breast cancer. With regard to disease-free survival analysis, the WT1 high expression group showed worse prognosis than the low expression group in univariate analysis, and WT1 was demonstrated to be an independent prognostic indicator in multivariate analysis. This study confirms an oncogenic role of WT1 and demonstrates a possible relation between WT1 and progression of breast cancer.
\end{abstract}

\section{Introduction}

Breast cancer is the most common cancer and the leading cause of cancer death among women all over the world (1). Development and progression of breast cancer depend on the balance of oncogenes and tumor suppressor genes (2). Identification and characterization of these genes will lead to discovery of new markers and potential therapeutic targets for prevention and treatment of breast cancer (3).

Correspondence to: Professor Jun Jiang, Breast Disease Center, Southwest Hospital, Third Military Medical University, 29 Gaotanyan Street, Chongqing, P.R. China

E-mail: jcbd@medmail.com.cn

${ }^{*}$ Contributed equally

Key words: breast cancer, Wilms' tumor 1, molecular subtype, prognosis
Wilms' tumor 1 (WT1) gene was originally identified as a tumor suppressor gene, which is responsible for Wilms tumor $(4,5)$. However, accumulating evidence indicated that WT1 may play an oncogenic role in leukemogenesis and tumorigenesis (6-11). It was shown that the growth of leukemic cells and a variety of solid cancer cells was inhibited by knockdown of WT1 expression, while forced expression of WT1 promoted cell growth and motility, suppressed apoptosis and induced leukemia in WT1-transgenic mice (9).

WT1 protein and mRNA were firstly found to be expressed in the normal breast tissue, but absent in $>90 \%$ of the breast cancer (12), and WT1 inhibited proliferation and tumorigenesis of breast cancer cells, indicating WT1 served as a tumor suppressor gene in breast cancer (13-15). On the contrary, a number of studies demonstrated that wild-type WT1 gene plays an important role in the development of breast cancer (16). Loeb et al reported that WT1 could be detected in $87 \%$ of primary breast carcinomas, but not in normal breast epithelium (17). Miyoshi et al found that WT1 mRNA significantly correlated with the poor prognosis of breast cancer (18). In addition, WT1 could promote the proliferation and restrain the apoptosis of breast cancer cells (19-21), all of which indicate that WT1 might serve as an oncogene in breast cancer. Therefore, it is necessary to clarify the oncogenic or tumor suppressive role of WT1 in breast cancer. Moreover, relationship between WT1 expression and clinicopathological parameters and prognosis of breast cancer was inconsistent so far $(12,18,22,23)$, and the possible correlation between WT1 expression and molecular subtypes has not been reported.

In this study, we analyzed the WT1 mRNA expression in a microarray dataset of 266 early breast cancer patients and investigated its possible relationship with the clinicopathological parameters, molecular subtypes and prognosis so as to explore the role of WT1 gene in breast cancer.

\section{Materials and methods}

Tumor samples. The publicly available microarray dataset, GSE21653, was collected from National Center for Biotechnology Information (NCBI) Gene Expression Omnibus (GEO). 

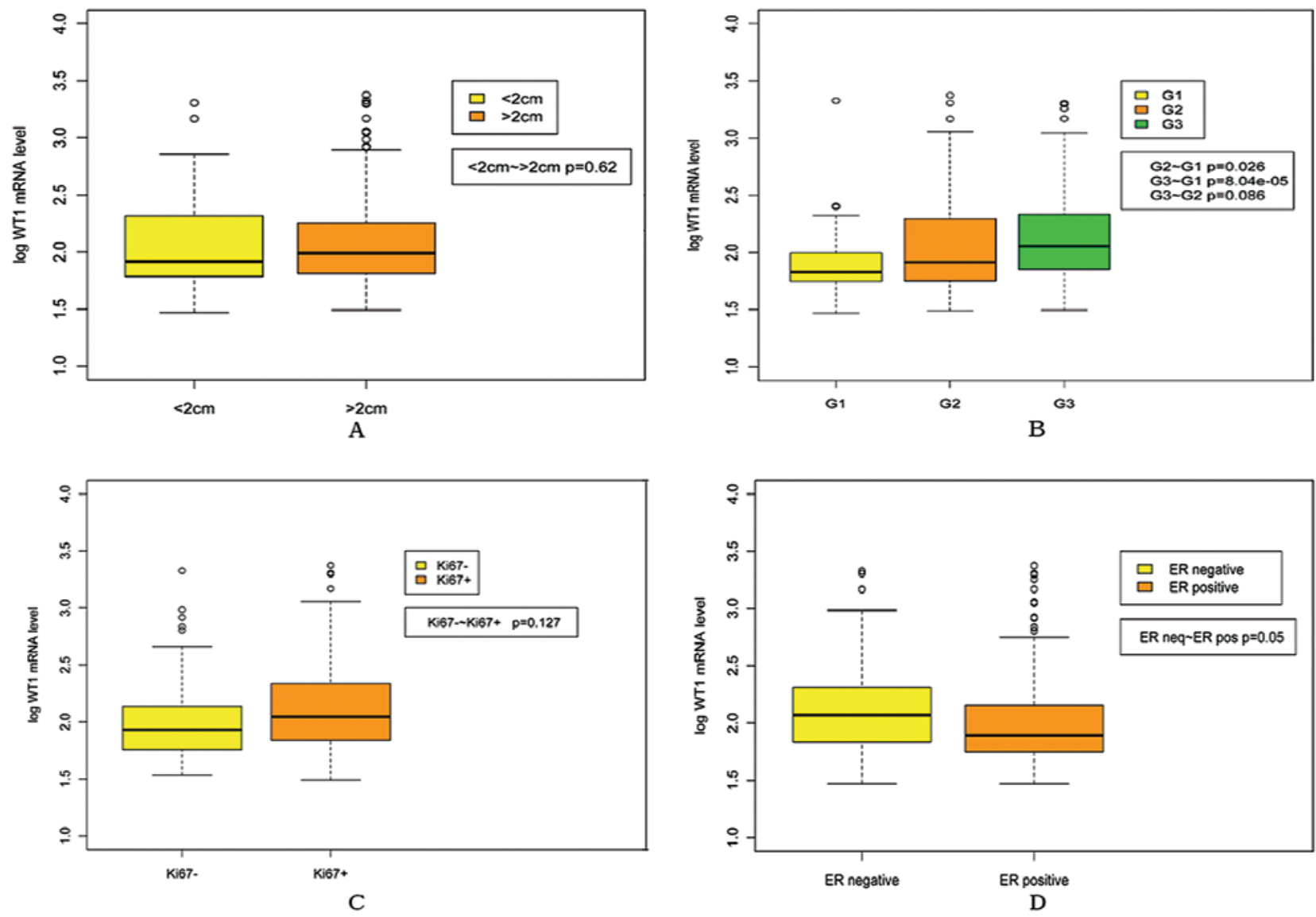

Figure 1. Relationship between WT1 mRNA expression and clinicopathological factors of breast cancer in GSE21653. Comparison of WT1 mRNA expression among (A) pT $<2 \mathrm{~cm}$ and $>2 \mathrm{~cm}$ groups, (B) G1, G2 and G3 groups, (C) Ki67 negative (-) and Ki67 positive (+) groups, and (D) ER negative (-) and ER positive (+) groups.

Table I. Univariate analysis of relationship between WT1 mRNA expression and DFS.

\begin{tabular}{lccccccr}
\hline $\begin{array}{l}\text { Cutoff } \\
\text { value }\end{array}$ & Survival & HR & $95 \%$ CI & $\begin{array}{c}\text { Log-rank } \\
\text { (P-value) }\end{array}$ & $\begin{array}{c}\text { High } \\
\text { level (N) }\end{array}$ & $\begin{array}{c}\text { Low } \\
\text { level (N) }\end{array}$ & N \\
\hline 2.1 & DFS & 1.226 & $(0.794,1.895)$ & 0.357 & 106 & 146 & 252 \\
3.1 & DFS & 3.294 & $(1.198,9.055)$ & 0.014 & 7 & 245 & 252 \\
\hline
\end{tabular}

DFS, disease-free survival; HR, hazard ratio; CI, confidence interval.

GSE21653 involved 266 early breast cancer patients, who underwent initial surgery in Institut Paoli-Calmettes (IPC) institution between 1992 and 2004 (24). They included 227 cases previously reported and 39 additional cases, all of which were similarly profiled using Affymetrix U133 Plus 2.0 human oligonucleotide microarrays (25). Clinicopathological characteristics of the patients have been described previously $(24,25)$. Among them, a total of 252 patients had the DFS information.

Microarray analysis. Regarding the Affymetrix-based datasets, GSE21653, we used Robust Multichip Average (RMA) with the nonparametric quantile algorithm as normalization parameter (26). RMA was applied to the raw data from the IPC series. Quantile normalization or RMA was done in R using bioconductor (27) and associated packages. Then the $\log ^{2}$ transformed data for the following WT1 probes were evaluated. Patients were stratified based on the main available prognostic factors for breast cancer, such as pathological tumor size (pT), histological grades (Grade 1, G1; Grade 2, G2; Grade 3, G3) according to Searff-Bloom-Richardson (SBR) staging system, Ki67, estrogen receptor (ER), molecular subtypes (basal-like, ERBB2, luminal A, luminal B and normal-like; luminal: luminal A and luminal B) and diseasefree survival (DFS).

Statistical analysis. T-test was used to investigate whether the WT1 gene expression values were significantly different between any two compared groups of different disease characteristics with $\mathrm{P}<0.05(28,29)$. DFS analyses were performed during the period from the date of diagnosis to the first obser- 


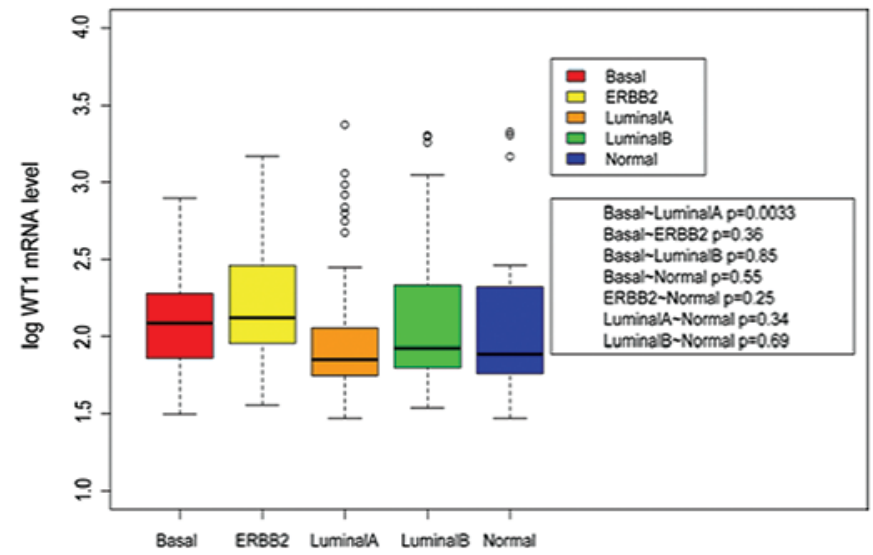

A

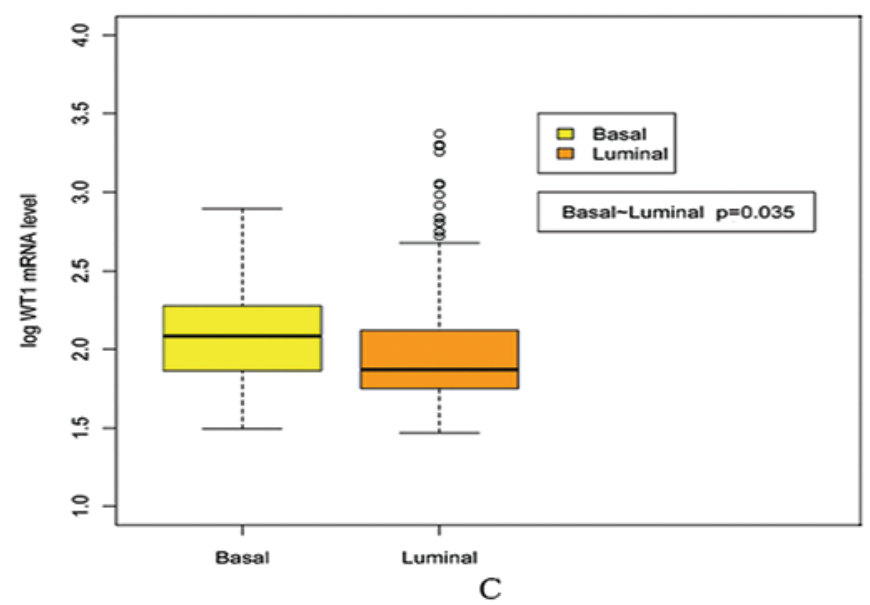

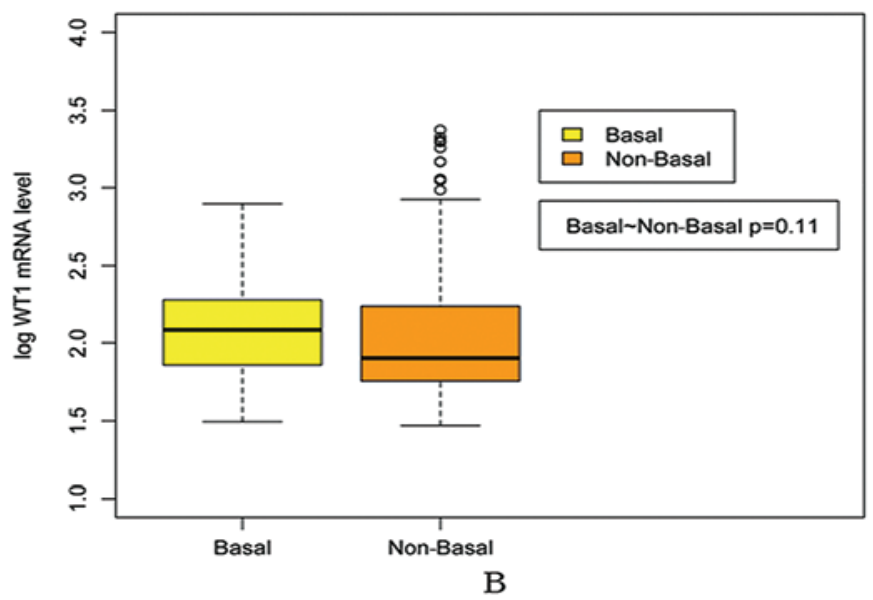

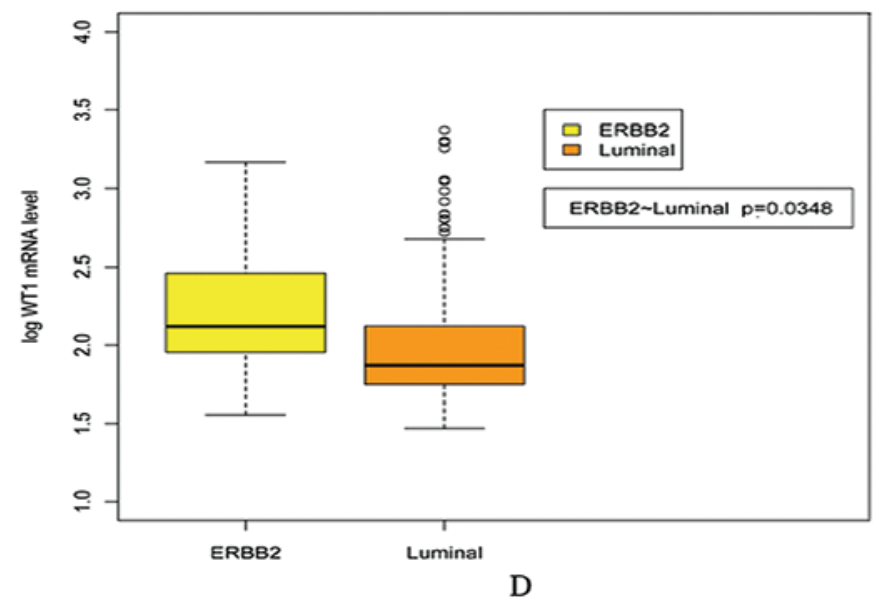

Figure 2. Relationship between WT1 mRNA expression and molecular subtypes of breast cancer in GSE21653. Comparison of WT1 mRNA expression among (A) basal-like, ERBB2, luminal A, luminal B and normal subtypes, (B) basal-like and non-basal-like subtypes, (C) basal-like and luminal subtypes, and (D) ERBB2 and luminal subtypes.

vation of any metastasis. DFS was estimated according to the Kaplan-Meier method and analyzed by log-rank (Mantel-Cox) test. Hazard ratio (HR) and $95 \%$ confidence interval (CI) were estimated by use of a stratified Cox regression analysis. Multivariate analysis was done by incorporating all variables with a P-value $<0.05$ in univariate analysis.

All statistical tests were two-sided at the $5 \%$ level of significance. Statistical analysis was done using the survival package (version 2.36) in the R software (version 2.12.1).

\section{Results}

Relationship between WT1 mRNA expression and clinicopathological factors and molecular subtypes of breast cancer. As shown in Fig. 1, WT1 mRNA expression increased in relation to histological grades (G2 vs. $\mathrm{G} 1, \mathrm{P}=0.026$; $\mathrm{G} 3$ vs $\mathrm{G} 1, \mathrm{P}=8.04 \mathrm{e}-5)$. In addition, WT1 mRNA expression was significantly higher in ER negative group than in ER positive group $(\mathrm{P}=0.050)$. However, no correlation was found between WT1 mRNA expression and pT ( $<2 \mathrm{~cm}$ vs. $>2 \mathrm{~cm}$, $\mathrm{P}=0.620$ ) and Ki67 expression (Ki67 positive vs. Ki67 negative, $\mathrm{P}=0.127$ ). As shown in Fig. 2, WT1 mRNA expression was significantly higher in basal-like and ERBB2 subtypes than in luminal subtype $(\mathrm{P}=0.003$ for basal-like vs. luminal
$\mathrm{A}, \mathrm{P}=0.035$ for basal-like vs. luminal, $\mathrm{P}=0.035$ for $\mathrm{ERBB} 2$ vs. luminal).

Univariate analysis of WT1 mRNA expression and DFS in GSE21653. Patients were divided into the WT1 high and low mRNA expression groups according to the cutoff value of 2.1, which corresponded to the mean of the WT1 mRNA levels in total breast cancer tissues and the cutoff value of 3.1, which corresponded to the mean +2 standard deviation of the WT1 mRNA levels of the normal-like breast subtype, considering its intrinsic gene expression patterns $(30,31)$ and WT1 expression level in this study (Fig. 2A). Kaplan-Meier analyses of the probability that patients would remain free of distant metastases were carried out between WT1 high and low expression groups. As shown in Fig. 3 and Table I, there was no significant difference of DFS between the WT1 high and low expression group $(\mathrm{HR}=1.226,95 \% \mathrm{CI}=0.794-1.895, \mathrm{P}=0.357)$ with the 2.1 cutoff value, however, WT1 high expression group showed a significantly lower DFS than the low expression group $(\mathrm{HR}=3.294$, $95 \% \mathrm{CI}=1.198-9.055, \mathrm{P}=0.014)$ with the 3.1 cutoff value.

Multivariate analysis of WT1 mRNA expression and DFS in GSE21653. Using the Cox proportional hazards model, multivariate analysis demonstrated that grades are the 

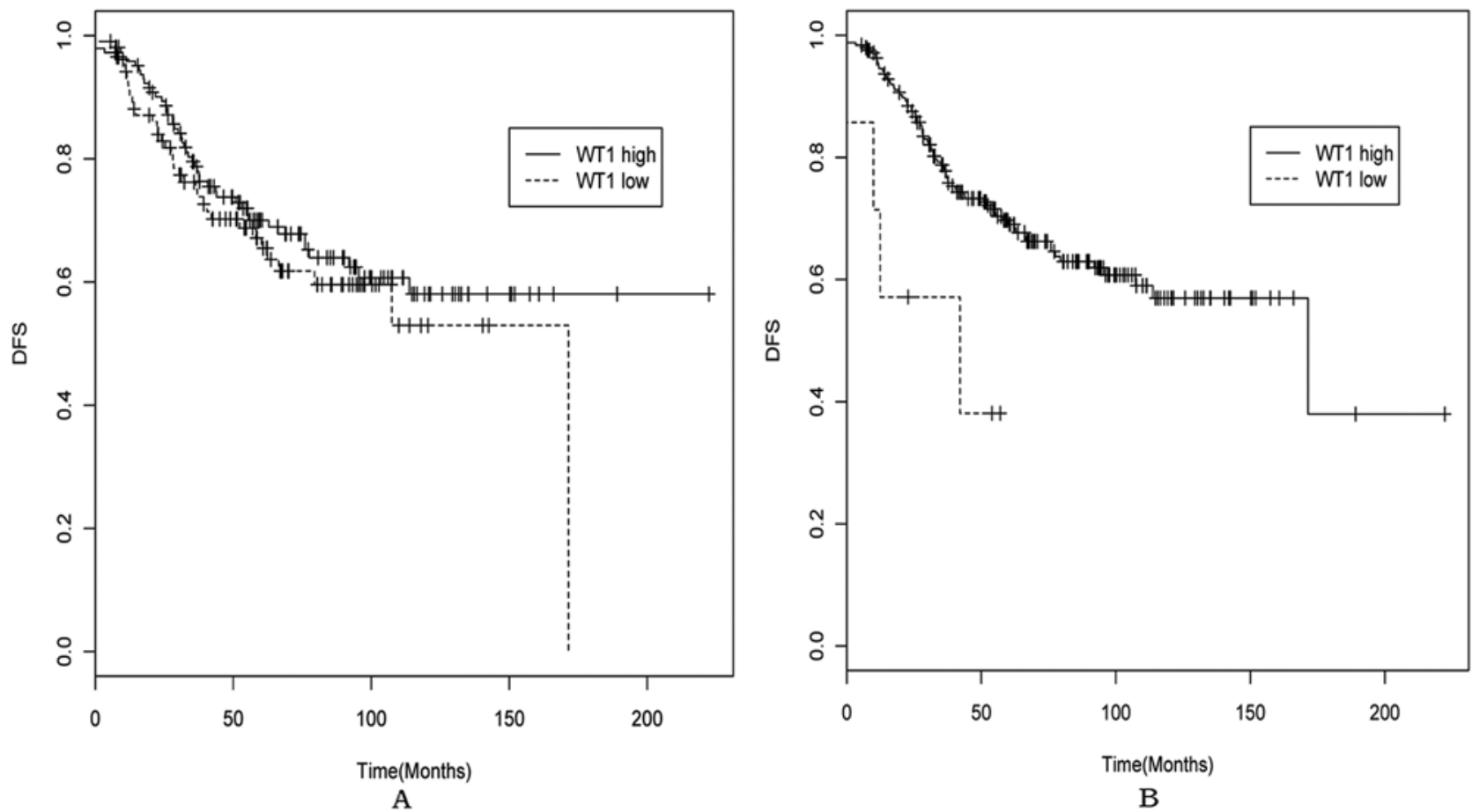

Figure 3. Univariate analysis of relationship between WT1 mRNA expression and DFS of breast cancer patients in the GSE21653. (A and B) stand for survival curve when using the 2.1 and 3.1 cutoff value to define high and low WT1 mRNA expression group, respectively.

Table II. Multivariable proportional-hazards analysis of DFS based on 2.1 cutoff value.

\begin{tabular}{|c|c|c|}
\hline Variable & HR $(95 \% \mathrm{CI})$ & P-value \\
\hline WT1 values (high vs. low) & $1.093(0.687-1.740)$ & 0.708 \\
\hline Grade (G2 vs. G1) & $2.611(1.133-6.019)$ & 0.024 \\
\hline Grade (G3 vs. G1) & $2.993(1.249-7.171)$ & 0.014 \\
\hline pT $(<2 \mathrm{~cm}$ vs. $>2 \mathrm{~cm})$ & $1.162(0.662-2.040)$ & 0.601 \\
\hline ER (ER positive vs. ER negative) & $0.675(0.380-1.197)$ & 0.179 \\
\hline Subtype (basal vs. non-basal) & $1.357(0.703-2.619)$ & 0.363 \\
\hline
\end{tabular}

pT, pathological tumor size; ER, estrogen receptor; HR, hazard ratio; CI, confidence interval.

Table III. Multivariable proportional-hazards analysis of DFS based on 3.1 cutoff value.

\begin{tabular}{lcc}
\hline Variable & Hazard ratio (95\% CI) & P-value \\
\hline WT1 values (high vs. low) & $\mathbf{3 . 4 5 4}(\mathbf{1 . 2 0 3 - 9 . 9 1 8 )}$ & $\mathbf{0 . 0 2 1}$ \\
Grade (G2 vs. G1) & $2.385(0.961-5.924)$ & 0.061 \\
Grade (G3 vs. G1) & $\mathbf{3 . 1 2 1}(\mathbf{1 . 2 3 6 - 7 . 8 8 3 )}$ & $\mathbf{0 . 0 1 6}$ \\
pT $(<2$ cm vs. $>2$ cm) & $0.967(0.523-1.789)$ & 0.916 \\
ER (ER positive vs. ER negative) & $0.628(0.330-1.196)$ & 0.157 \\
Subtype (basal vs. non-basal) & $1.203(0.572-2.534)$ & 0.626
\end{tabular}

pT, pathological tumor size; ER, estrogen receptor; HR, hazard ratio; CI, confidence interval.

strongest predictor of the likelihood of DFS $(\mathrm{HR}=2.611,95 \%$ $\mathrm{CI}=1.133-6.019, \mathrm{P}=0.024$ for $\mathrm{G} 2$ vs. $\mathrm{G} 1 ; \mathrm{HR}=2.993,95 \%$ $\mathrm{CI}=1.249-7.171, \mathrm{P}=0.014$ for $\mathrm{G} 3$ vs. $\mathrm{G} 1$ ), when using the 2.1 cutoff value (Table II). However, with the 3.1 cutoff value, multivariate analysis demonstrated that both grades $(\mathrm{HR}=3.121$, 95\% $\mathrm{CI}=1.236-7.883, \mathrm{P}=0.016$ for $\mathrm{G} 3$ vs. G1) and WT1 mRNA 
expression $(\mathrm{HR}=3.454,95 \% \mathrm{CI}=1.203-9.918, \mathrm{P}=0.021$ for high expression group vs. low expression group) are independent prognostic indicators for breast cancer (Table III).

\section{Discussion}

The WT1 gene, located at chromosome 11p13, encodes a DNA-binding protein, which contains an NH2-terminal glutamine and proline-rich domain involved in transcriptional repression and activation and $\mathrm{C}$-terminal domain composed of four Cys-Cys-His-His-type zinc finger domains (ZF) involved in DNA and RNA binding and protein-protein interactions (32). WT1 regulates a diverse array of genes through ZF domain at GC-rich sites (32), playing an important role in cell growth and development $(6-11,33)$.

Though originally isolated as a tumor suppressor gene responsible for Wilms' tumor, WT1 is found to be overexpressed in primary human leukemia and a variety of solid tumors, including lung, colon, liver, thyroid and pancreatic ductal cancer $(9,34,35)$. In addition, knockdown of WT1 by shRNA induced mitochondrial damage and the resultant apoptosis in several WT1-expressing solid tumor cells, indicating that WT1 might play an oncogenic role in these tumors (36).

Up to now, the role and function of WT1 in breast cancer have been not clarified. As for expression of WT1 in breast tissues, the groups of Silberstein and Loeb obtained contrary results in the clinical reports $(12,17)$. As for function of WT1 in breast cancer cells, a promoting or repressing effect of WT1 on breast cancer cells was observed in the experimental studies, making it hard to conclude on role of WT1 in breast cancer. In addition, some studies have focused on WT1 expression in breast cancer, but results are not clear enough to demonstrate its possible relationship with tumor biology.

In this study, we found that WT1 expression was higher in ER-negative patients than in ER-positive patients, which may be explained by the fact that overexpression of WT1 directly resulted in the down-regulation of ER expression (22). In addition, our results also demonstrated that WT1 tended to be overexpressed in tumors with high histological grades. It has been well established that breast cancer patients with ERBB2-overexpression and basal-like molecular subtypes had worse prognosis than luminal subtypes (31). Of note, our present data showed that WT1 mRNA expression was much higher in patients with ERBB2 and basal tumors. To the best of our knowledge, this is the first report exploring the possible relationship between WT1 and molecular subtypes, and the preliminary results suggest a potential role of WT1 in progression of breast cancer. Though Miyoshi et al (18) found that the prognosis of patients with high WT1 expression was significantly worse than that in patients with low WT1 expression, Camcr et al failed to confirm this finding in a later study (23). In the present study, we concluded that WT1 mRNA high expression predicted poor prognosis of breast cancer patients when using 3.1 as cutoff value, which might be due to the facts that WT1 could promote proliferation, invasion, migration, response to hypoxia and drug resistance of cancer cells $(19-22,35,37,38)$.

Conclusively, our study demonstrates association between WT1 mRNA levels and histological grade, ER status, molecular subtype and clinical outcome of breast cancer, consistent with the hypothesis that WT1 plays an oncogenic role in breast cancer. However, further research is required to confirm the current findings and clarify the functions and relevant mechanisms of WT1 in human breast cancer.

\section{Acknowledgements}

This study was supported by grants from the National Natural Science Foundation of China (No. 81102030). We thank Miss Jun-Lan Liu, from Breast Disease Center, Southwest Hospital, Third Military Medical University, Chongqing, China, for language editing of the manuscript. We also would like to thank for the kind help of bioinformatics analysis from Fenghe (Shanghai) Information Technology Co., Ltd.

\section{References}

1. Jemal A, Bray F, Center MM, Ferlay J, Ward E and Forman D: Global Cancer Statistics. CA Cancer J Clin 61: 69-90, 2011.

2. Hanahan D and Weinberg RA: Hallmarks of cancer: the next generation. Cell 144: 646-674, 2011.

3. Gumireddy K, Li A, Gimotty PA, Klein-Szanto AJ, Showe LC, Katsaros D, et al: KLF17 is a negative regulator of epithelialmesenchymal transition and metastasis in breast cancer. Nat Cell Biol 11: 1297-1304, 2009.

4. Haber DA, Buckler AJ, Glaser T, Call KM, Pelletier J, Sohn RL, et al: An internal deletion within an $11 \mathrm{p} 13$ zinc finger gene contributes to the development of Wilms' tumor. Cell 61: 1257-1269, 1990.

5. Little $\mathrm{M}$ and Wells C: A clinical overview of WT1 gene mutations Hum Mutat 9: 209-225, 1997.

6. Loeb DM and Sukumar S: The role of WT1 in oncogenesis: tumor suppressor or oncogene? Int J Hematol 76: 117-126, 2002.

7. Hohenstein P and Hastie ND: The many facets of the Wilms tumour gene, WT1. Hum Mol Genet 15: R196-R201, 2006.

8. Yang L, Han Y, Suarez Saiz F and Minden MD: A tumor suppressor and oncogene: the WT1 story. Leukemia 21: 868-876, 2007.

9. Sugiyama H: WT1 (Wilms' tumor gene 1): biology and cancer immunotherapy. Jpn J Clin Oncol 40: 377-387, 2010.

10. Huff V: Wilms' tumours: about tumour suppressor genes, an oncogene and a chameleon gene. Nat Rev Cancer 11: 111-121, 2011.

11. Oji Y, Ogawa H, Tamaki H, Oka Y, Tsuboi A, Kim EH, et al: Expression of the Wilms' tumor gene WT1 in solid tumors and its involvement in tumor cell growth. Jpn J Cancer Res 90: 194-204, 1999.

12. Silberstein GB, Van Horn K, Strickland P, Roberts CT Jr and Daniel CW: Altered expression of the WT1 wilms tumor suppressor gene in human breast cancer. Proc Natl Acad Sci USA 94: 8132-8137, 1997.

13. Zhang TF, Yu SQ, Guan LS and Wang ZY: Inhibition of breast cancer cell growth by the Wilms' tumor suppressor WT1 is associated with a destabilization of beta-catenin. Anticancer Res 23: 3575-3584, 2003.

14. Reizner N, Maor S, Sarfstein R, Abramovitch S, Welshons WV, Curran EM, et al: The WT1 Wilms' tumor suppressor gene product interacts with estrogen receptor-alpha and regulates IGF-I receptor gene transcription in breast cancer cells. J Mol Endocrinol 35: 135-144, 2005.

15. Wang L and Wang ZY: The Wilms' tumor suppressor WT1 inhibits malignant progression of neoplastigenic mammary epithelial cells. Anticancer Res 28: 2155-2160, 2008.

16. Oji Y, Miyoshi Y, Kiyotoh E, Koga S, Nakano Y, Ando A, et al: Absence of mutations in the Wilms' tumor gene WT1 in primary breast cancer. Jpn J Clin Oncol 34: 74-77, 2004.

17. Loeb DM, Evron E, Patel CB, Sharma PM, Niranjan B, Buluwela L, et al: Wilms' tumor suppressor gene (WT1) is expressed in primary breast tumors despite tumor-specific promoter methylation. Cancer Res 61: 921-925, 2001.

18. Miyoshi Y, Ando A, Egawa C, Taguchi T, Tamaki Y, Tamaki H, et al: High expression of Wilms' tumor suppressor gene predicts poor prognosis in breast cancer patients. Clin Cancer Res 8: 1167-1171, 2002. 
19. Zapata-Benavides P, Tuna M, Lopez-Berestein G and Tari AM Downregulation of Wilms' tumor 1 protein inhibits breast cancer proliferation. Biochem Biophys Res Commun 295: 784-790, 2002.

20. Tuna M, Chavez-Reyes A and Tari AM: HER2/neu increases the expression of Wilms' Tumor 1 (WT1) protein to stimulate S-phase proliferation and inhibit apoptosis in breast cancer cells. Oncogene 24: 1648-1652, 2005.

21. Caldon CE, Lee CS, Sutherland RL and Musgrove EA: Wilms' tumor protein 1: an early target of progestin regulation in T-47D breast cancer cells that modulates proliferation and differentiation. Oncogene 27: 126-138, 2008.

22. Han Y, Yang L, Suarez-Saiz F, San-Marina S, Cui J and Minden MD: Wilms' tumor 1 suppressor gene mediates antiestrogen resistance via down-regulation of estrogen receptor-alpha expression in breast cancer cells. Mol Cancer Res 6: 1347-1355, 2008.

23. Camcı C, Kalender ME, Paydaş S, Sevinç A, Zorludemir S and Suner A: Prognostic significance of Wilms Tumor 1 (WT1) protein expression in breast cancer. Gaziantep Med J 17: 67-72, 2011.

24. Sabatier R, Finetti P, Cervera N, Lambaudie E, Esterni B, Mamessier E, et al: A gene expression signature identifies two prognostic subgroups of basal breast cancer. Breast Cancer Res Treat 126: 407-420, 2011.

25. Finetti P, Cervera N, Charafe-Jauffret E, Chabannon C, Charpin C, Chaffanet $\mathrm{M}$, et al: Sixteen-kinase gene expression identifies luminal breast cancers with poor prognosis. Cancer Res 68 : 767-776, 2008

26. Irizarry RA, Hobbs B, Collin F, Beazer-Barclay YD, Antonellis KJ Scherf U, et al: Exploration, normalization, and summaries of high density oligonucleotide array probe level data. Biostatistics 4: 249-264, 2003.

27. Nie H, Neerincx PB, van der Poel J, Ferrari F, Bicciato S, Leunissen JA, et al: Microarray data mining using Bioconductor packages. BMC Proc 3: S9, 2009.

28. Crawford JR and Garthwaite PH: Single-case research in neuropsychology: A comparison of five forms of t-test for comparing a case to controls. Cortex: Jul 23, 2011 (Epub ahead of print).
29. Diboun I, Wernisch L, Orengo CA and Koltzenburg M: Microarray analysis after RNA amplification can detect pronounced differences in gene expression using limma. BMC Genomics 7: $252,2006$.

30. Perou CM, Sørlie T, Eisen MB, van de Rijn M, Jeffrey SS, Rees CA, et al: Molecular portraits of human breast tumours. Nature 406: 747-752, 2000.

31. Sørlie T, Perou CM, Tibshirani R, Aas T, Geisler S, Johnsen H, et al: Gene expression patterns of breast carcinomas distinguish tumor subclasses with clinical implications. Proc Natl Acad Sci USA 98: 10869-10874, 2001.

32. Stoll R, Lee BM, Debler EW, Laity JH, Wilson IA, Dyson HJ, et al: Structure of the Wilms tumor suppressor protein zinc finger domain bound to DNA. J Mol Biol 372: 1227-1245, 2007.

33. Martínez-Estrada OM, Lettice LA, Essafi A, Guadix JA, Slight J, Velecela $\mathrm{V}$, et al: $\mathrm{Wtl}$ is required for cardiovascular progenitor cell formation through transcriptional control of Snail and E-cadherin. Nat Genet 42: 89-93, 2010.

34. Sera T, Hiasa Y, Mashiba T, Tokumoto Y, Hirooka M, Konishi I, et al: Wilms' tumour 1 gene expression is increased in hepatocellular carcinoma and associated with poor prognosis. Eur J Cancer 44: 600-608, 2008.

35. Perugorria MJ, Castillo J, Latasa MU, Goni S, Segura V, Sangro B, et al: Wilms' tumor 1 gene expression in hepatocellular carcinoma promotes cell dedifferentiation and resistance to chemotherapy. Cancer Res 69: 1358-1367, 2009.

36. Tatsumi N, Oji Y, Tsuji N, Tsuda A, Higashio M, Aoyagi S, et al: Wilms' tumor gene WT1-shRNA as a potent apoptosis-inducing agent for solid tumors. Int J Oncol 32: 701-711, 2008.

37. McCarty G, Awad O and Loeb DM: WT1 protein directly regulates expression of vascular endothelial growth factor and is a mediator of tumor response to hypoxia. J Biol Chem 286: 43634-43643, 2011.

38. Jomgeow T, Oji Y, Tsuji N, Ikeda Y, Ito K, Tsuda A, et al: Wilms' tumor gene WT1 17AA(-)/KTS(-) isoform induces morphological changes and promotes cell migration and invasion in vitro. Cancer Sci 97: 259-270, 2006. 